\section{Original} article

Kaiser Permanente Research Department, Atlanta, Georgia, USA R A Diseker, III

\section{Centers for Disease Control and Prevention, National Center for HIV, STD and TB Prevention, Division of HIVIAIDS Prevention, Atlanta, Georgia, USA \\ T A Peterman M L Kamb \\ Project RESPECT Study Group, San Francisco Health Department, San Francisco, California, USA \\ C Kent \\ Project RESPECT Study Group, Baltimore City Heath Department and Johns Hopkins University, Baltimore, Maryland, USA \\ J M Zenilman}

Project RESPECT Study Group, Denver Department of Public Health, Denver, Colorado, USA

J M Douglas, Jr

Project RESPECT Study Group, Long Beach Health Department and California State University, Long Beach, California , USA

F Rhodes

Project RESPECT Study Group, New Jersey Health Department and Newark STD Clinic, Newark, New Jersey, USA

M Iatesta

Correspondence to: Robert A Diseker, III, Kaiser Permanente Research Department, Nine Piedmont Center, 3495 Piedmont Road, NE, Atlanta, GA 30305-1736, USA robert.diseker@kp.org

\title{
Circumcision and STD in the United States: cross sectional and cohort analyses
}

\author{
Robert A Diseker, III, Thomas A Peterman, Mary L Kamb, Charlotte Kent,
} Jonathan M Zenilman, John M Douglas, Jr, Fen Rhodes, Michael Iatesta

Background: Male circumcision status has been shown to be associated with sexually transmitted disease (STD) acquisition in some, but not all, studies. Most studies have been cross sectional. Objectives: We examined the association between circumcision status and the prevalence and incidence of gonorrhoea, chlamydia, and syphilis.

Methods: We analysed cross sectional and cohort study data from a multicentre controlled trial in the United States. Between July 1993 and September 1996, 2021 men visiting public inner city STD clinics in the United States were examined by a clinician at enrolment and 1456 were examined at follow up visits 6 and 12 months later. At each visit, men had laboratory tests for gonorrhoea, chlamydia, and syphilis and were examined for circumcision status. We used multiple logisitic regression to compare STD risk among circumcised and uncircumcised men adjusted for potentially confounding factors.

Results: Uncircumcised men were significantly more likely than circumcised men to have gonorrhoea in the multivariate analyses, adjusted for age, race, and site, in both the cross sectional (odds ratio (OR), 1.3; 95\% confidence interval (CI), 0.9 to 1.7 ) and in the cohort analysis (OR, $1.6 ; 95 \%$ CI, 1.0 to 2.6 ). There was no association between lack of circumcision and chlamydia in either the cross sectional (OR, 1.0; 95\% CI 0.7-1.4) or the cohort analysis (OR, 0.9; 95\% CI 0.5-1.5). The magnitude of association between lack of circumcision and syphilis was similar in the cross sectional (OR, 1.4; 95\% CI 0.6 to 3.3) and cohort analysis (OR, $1.5 ; 95 \%$ CI 0.4 to 6.1).

Conclusion: Uncircumcised men in the United States may be at increased risk for gonorrhoea and syphilis, but chlamydia risk appears similar in circumcised and uncircumcised men. Our results suggest that risk estimates from cross sectional studies would be similar to cohort findings. (Sex Transm Inf 2000;76:474-479)

Keywords: circumcision; sexually transmitted diseases; United States

\section{Background}

Several studies have shown that compared with circumcised men, uncircumcised men are at higher risk for acquiring some sexually transmitted diseases (STDs) including chancroid, chlamydia, gonorrhoea, syphilis, ${ }^{1-13}$ and lower risk for acquiring genital herpes and genital warts. ${ }^{14} 15$ Other studies, however, found no association between STD acquisition and circumcision status. ${ }^{16-20}$ Only a few studied US populations, and not all confirmed diagnosis with laboratory testing. Most studies used cross sectional designs; only four were prospective studies which provide a better measure of STD risk because they ascertain incident cases of disease. ${ }^{4813}$ The more troublesome concern is that these cross sectional studies are typically conducted in STD clinics where there is a strong potential for selection bias. The relation between circumcision status and STD in the STD clinic may not be the same as the relation in the community. For example, circumcised men in the community may be more likely than uncircumcised men to come to the clinic with a problem not caused by an STD. If this occurred, it would appear that circumcised men were protected from STD in a clinic based study (Berkson's bias). This bias could be overcome using a prospective study design where follow up did not depend on the development of symptoms. We analysed the role of circumcision status in the acquisition of STDs in a cross sectional and a longitudinal follow up study that included multiple examinations.

\section{Methods}

STUDY POPULATION

We used data collected from a randomised controlled trial of HIV prevention counselling efficacy. ${ }^{21}$ The study population included men who visited public inner city STD clinics between July 1993 and September 1996 and enrolled in Project RESPECT. The STD clinics were in Baltimore, Maryland; Denver, Colorado; Long Beach, California; Newark, New Jersey; and San Francisco, California. Participants were heterosexual patients 15 years or older who came to the clinics for an STD examination, spoke English, and who reported having had vaginal sex in the past 30 days. All participants gave written, informed consent, and members of institutional review boards at each site reviewed and approved the trial protocol. Participants were examined by a clinician (registered nurse, nurse practitioner, physician's assistant, or physician) at enrolment and at follow up visits 6 and 12 months later. They were also examined if they revisited the clinic at other times for a 
Table 1 Cross sectional analysis: associations between participant characteristics and sexually transmitted diseases $(N=2021)$

\begin{tabular}{|c|c|c|c|c|c|c|c|c|}
\hline & \multirow[b]{3}{*}{ Total } & \multirow{3}{*}{$\begin{array}{l}\text { Without } \\
\text { STD } \\
(n=834)\end{array}$} & \multicolumn{6}{|c|}{ Baseline STD $\neq$} \\
\hline & & & \multicolumn{2}{|c|}{$\begin{array}{l}\text { Gonorrhoea } \\
(n=404)\end{array}$} & \multicolumn{2}{|c|}{$\begin{array}{l}\text { Chlamydia } \\
(n=312)\end{array}$} & \multicolumn{2}{|c|}{$\begin{array}{l}\text { Syphilis } \\
(n=28)\end{array}$} \\
\hline & & & OR & p Value & $O R$ & p Value & OR & $p$ Value \\
\hline \multicolumn{9}{|l|}{ Circumcised } \\
\hline Yes & 1518 & 622 & 1.0 & - & 1.0 & - & 1.0 & - \\
\hline No & 503 & 212 & 1.1 & 0.50 & 0.9 & 0.41 & 1.6 & 0.22 \\
\hline \multicolumn{9}{|l|}{ Site } \\
\hline Baltimore & 377 & 101 & 8.7 & $<0.001$ & 2.5 & $<0.001$ & 1.2 & 0.80 \\
\hline Denver & 393 & 155 & 4.3 & $<0.001$ & 1.0 & 0.90 & 0.8 & 0.76 \\
\hline Long Beach & 332 & 132 & 3.3 & $<0.001$ & 0.9 & 0.62 & 0.3 & 0.16 \\
\hline Newark & 476 & 195 & 1.5 & 0.01 & 1.0 & 0.87 & 0.4 & 0.23 \\
\hline San Francisco & 443 & 251 & 1.0 & - & 1.0 & - & 1.0 & - \\
\hline \multicolumn{9}{|l|}{ Race/ethnicity } \\
\hline White & 364 & 204 & 1.0 & - & 1.0 & - & 1.0 & - \\
\hline African-American & 1259 & 424 & 15.5 & $<0.001$ & 3.4 & $<0.001$ & 12.0 & 0.02 \\
\hline Hispanic & 300 & 152 & 3.3 & 0.001 & 2.0 & 0.005 & 2.7 & 0.42 \\
\hline Other & 98 & 54 & 3.8 & 0.003 & 2.1 & 0.03 & - & - \\
\hline \multicolumn{9}{|l|}{ Age } \\
\hline$<20$ & 276 & 87 & 2.3 & $<0.001$ & 6.8 & $<0.001$ & - & - \\
\hline $20-24$ & 584 & 210 & 1.8 & $<0.001$ & 4.7 & $<0.001$ & 0.4 & 0.09 \\
\hline $25-29$ & 413 & 171 & 1.1 & 0.72 & 2.6 & $<0.001$ & 0.7 & 0.45 \\
\hline $30-34$ & 326 & 154 & 1.1 & 0.76 & 2.0 & 0.02 & 0.9 & 0.79 \\
\hline$\geqslant 35$ & 422 & 212 & 1.0 & - & 1.0 & - & 1.0 & - \\
\hline \multicolumn{9}{|c|}{ No of sex partners past 3 monthst } \\
\hline 1 & 898 & 419 & 1.0 & - & 1.0 & - & 1.0 & - \\
\hline 2 & 584 & 226 & 1.9 & $<0.001$ & 1.2 & 0.19 & 0.7 & 0.54 \\
\hline$\geqslant 3$ & 535 & 186 & 2.2 & $<0.001$ & 1.7 & 0.001 & 1.1 & 0.91 \\
\hline \multicolumn{9}{|c|}{ New partner at baselinet } \\
\hline Yes & 1040 & 408 & 1.4 & 0.001 & 1.1 & 0.47 & 0.8 & 0.51 \\
\hline No & 970 & 421 & 1.0 & - & 1.0 & - & 1.0 & - \\
\hline
\end{tabular}

*People with each STD were compared with the group with no STD.

†Numbers in partners column do not total 2021 because of missing values.

checkup, evaluation of symptoms, or because of partner referral for STDs.

We performed a cross sectional analysis of prevalent STDs at baseline and a cohort analysis of incident STDs during the follow up period. This two part analysis allowed us to compare our cross sectional results with (1) those of other studies to determine if our results were similar and (2) those of our cohort to determine if the associations were similar between prevalent and incident data.

Circumcision status was assessed by study clinicians as part of the physical examinations. We excluded men with no circumcision status recorded at baseline and men whose circumcision status was recorded differently at baseline and follow up. The cross sectional study included men who were examined for STDs at baseline. Men diagnosed with gonorrhoea, chlamydia, or syphilis at the baseline visit were compared with a referent group without any STD at baseline - that is, did not have these or other STDs such as herpes, warts, and balanitis. The cohort study included men who returned for at least one follow up visit. Men diagnosed with gonorrhoea, chlamydia, or syphilis at any follow up visit were compared with a referent group without any STD during the follow up period. At baseline and follow up visits, the following STD tests were done; Gram stain of a smear prepared from a urethral swab specimen, culture for Neisseria gonorrhoeae, nucleic acid amplification assay for Chlamydia trachomatis using a first catch urine specimen, and syphilis serology on serum obtained by venepuncture.

Sexually transmitted diseases were defined by laboratory test results: gonorrhoea was a positive culture for $N$ gonorrhoeae or Gram negative intracellular diplococci on a Gram stain of a specimen obtained using a urethral swab; chlamydia was a positive $C$ trachomatis polymerase chain reaction from a urine specimen; syphilis was a suggestive history and physical examination with supportive treponemal and non-treponemal antibody test results.

Our multivariate models adjusted for the following factors as they potentially distort the true association between circumcision and disease status: study site, age group, race/ethnicity, number of sex partners, and sex with a new partner.

STATISTICAL ANALYSIS

We used SAS software version 6.12 (SAS Institute, Cary, NC, USA) to perform logistic regression, which estimated odds ratios (OR) and $95 \%$ confidence intervals (CI) for both analyses. The OR were computed by comparing each group of patients with a particular STD during the analysis period against a referent group with no STD during the analysis period. A multivariate model was built using backwards elimination at alpha $=0.05$ to identify final predictors of each disease. Beginning with a full model including all predictors, covariates were eliminated one at a time based on the highest $\mathrm{p}$ value for the relation between the predictor and disease. Log likelihood ratio tests were used to confirm the results.

\section{Results}

Of 3269 men enrolled in Project RESPECT, we omitted $812(25 \%)$ whose study group (by design) did not have standard laboratory tests performed, $403(12 \%)$ whose circumcision status was recorded differently on a subsequent visit, and $33(1 \%)$ whose circumcision status 
Table 2 Cross sectional analysis: associations between sexually transmitted diseases and uncircumcised status at baseline $(N=2021)$

\begin{tabular}{|c|c|c|c|c|c|}
\hline & \multicolumn{2}{|c|}{ Crude distribution (No) } & \multirow{2}{*}{$\begin{array}{l}\text { Crude } \\
\text { OR }\end{array}$} & \multirow{2}{*}{$\begin{array}{l}\text { Adjusted* } \\
\text { OR }\end{array}$} & \multirow[b]{2}{*}{$95 \% C I$} \\
\hline & Uncircumcised & Circumcised & & & \\
\hline Without STD $\dagger$ & 212 & 622 & 1.0 & 1.0 & \\
\hline Gonorrhoea & 110 & 294 & 1.1 & 1.3 & $0.9,1.7$ \\
\hline Chlamydia & 72 & 240 & 0.9 & 1.0 & $0.7,1.4$ \\
\hline Syphilis & 10 & 18 & 1.6 & 1.4 & $0.6,3.3$ \\
\hline
\end{tabular}

${ }^{\star}$ Each model adjusted for age group, race/ethnicity, and site.

$\dagger$ People with each STD were compared with the group with no STD.

was not recorded at any visit. A total of 2021 men remained in the cross sectional analysis. For the cohort analysis we also omitted 564 ( $28 \%$ of baseline) men who did not return for a follow up visit, and one who had no recorded STD examination results. A total of 1456 men remained in the cohort analysis.

At the enrolment visit, $69 \%$ of the men were categorised by the clinician as circumcised. Circumcision was more common among men aged $<35(72 \%)$ than those $>35(60 \%)$. Circumcision was more common among white men $(86 \%)$ than African-American $(68 \%)$ or Hispanic men (52\%). Circumcision status was not associated with having a new partner or with the number of partners at baseline or follow up. Follow up rates were similar between circumcised and uncircumcised men.

CROSS SECTIONAL ANALYSIS

Univariate analysis showed no statistically significant association between circumcision status and any of the STDs. However, STD diagnosis was associated to some extent with study site, race/ethnicity, age, and partners (table 1). African-American men were more likely than white men to be diagnosed with gonorrhoea, chlamydia, and syphilis, and men under the age of 25 were more likely than older men to be diagnosed with gonorrhoea and chlamydia. Men who had three or more partners in the past 3 months were more likely to be diagnosed with gonorrhoea or chlamydia than were men with fewer partners. Men with a new partner at baseline were more likely than men with no new partner to have gonorrhoea.

After we eliminated variables that were not statistically significantly associated with circumcision status such as number of sex partners and sex with a new partner, each multivariate model of disease adjusted for the potential effects of age group, patient race/ ethnicity, and study site (table 2). In the adjusted analysis, uncircumcised men were slightly more likely than circumcised men to have gonorrhoea (OR 1.3) or syphilis (OR 1.4), but these associations were not statistically significant at $\mathrm{p}<0.05$.

\section{COHORT ANALYSIS}

In the cohort study, characteristics associated with acquiring a new STD (table 3) closely resembled those found in the cross sectional analysis (table 1). Uncircumcised men had higher ORs for syphilis (1.9) and gonorrhoea (1.2), but the strengths of these associations were not statistically significant. The cohort study also found associations between disease and the different potential confounders. The incidence of most STDs was higher in Baltimore, Long Beach, and Newark. Compared with others, men younger than 25 years of age and men with an average of two or more partners during the follow up period were more likely to have had gonorrhoea or chlamydia. African-Americans were more likely than white people to have gonorrhoea or chlamydia. Having a new partner during follow up did not increase the risk for STD.

Table 3 Cohort analysis: associations between participant characteristics and sexually transmitted diseases $(N=1456)$

\begin{tabular}{|c|c|c|c|c|c|c|c|c|}
\hline & \multirow[b]{3}{*}{ Total } & \multirow{3}{*}{$\begin{array}{l}\text { Without } \\
\text { STD } \\
(n=855)\end{array}$} & \multicolumn{6}{|c|}{ Follow up STD } \\
\hline & & & \multicolumn{2}{|c|}{ Gonorrhoea $(n=119)$} & \multicolumn{2}{|c|}{ Chlamydia $(n=111)$} & \multicolumn{2}{|c|}{ Syphilis $(n=10)$} \\
\hline & & & $O R$ & p Value & $O R$ & p Value & $O R^{\star}$ & $p$ Value \\
\hline \multicolumn{9}{|l|}{ Circumcised } \\
\hline Yes & 1109 & 634 & 1.0 & - & 1.0 & - & 1.0 & - \\
\hline No & 347 & 221 & 1.2 & 0.31 & 0.8 & 0.24 & 1.9 & 0.32 \\
\hline \multicolumn{9}{|l|}{ Site } \\
\hline Baltimore & 229 & 106 & 6.3 & $<0.001$ & 2.4 & 0.04 & 2.4 & 0.30 \\
\hline Denver & 290 & 185 & 3.1 & $<0.001$ & 1.6 & 0.23 & 5.2 & 0.15 \\
\hline Long Beach & 252 & 161 & 6.1 & $<0.001$ & 0.8 & 0.52 & 4.6 & 0.19 \\
\hline Newark & 332 & 152 & 0.9 & 0.80 & 0.4 & 0.008 & 2.2 & 0.41 \\
\hline San Francisco & 353 & 251 & 1.0 & - & 1.0 & - & 1.0 & - \\
\hline \multicolumn{9}{|l|}{ Race/ethnicity } \\
\hline White & 287 & 208 & 1.0 & - & 1.0 & - & 1.0 & - \\
\hline African-American & 869 & 430 & 17.1 & $<0.001$ & 2.8 & $<0.001$ & - & - \\
\hline Hispanic & 227 & 166 & 2.9 & 0.12 & 1.2 & 0.70 & - & - \\
\hline Other & 73 & 51 & 4.1 & 0.09 & 0.6 & 0.48 & - & - \\
\hline \multicolumn{9}{|l|}{ Age } \\
\hline$<20$ & 177 & 85 & 3.0 & $<0.001$ & 6.8 & $<0.001$ & - & - \\
\hline $20-24$ & 397 & 210 & 1.8 & 0.05 & 4.6 & $<0.001$ & 0.4 & 0.20 \\
\hline $25-29$ & 294 & 192 & 1.1 & 0.86 & 2.1 & 0.07 & - & - \\
\hline $30-34$ & 252 & 147 & 1.2 & 0.66 & 2.0 & 0.12 & 0.5 & 0.40 \\
\hline$\geqslant 35$ & 336 & 221 & 1.0 & - & 1.0 & - & 1.0 & - \\
\hline \multicolumn{9}{|c|}{ No of sex partners past 3 monthst } \\
\hline 1 & 907 & 566 & 1.0 & - & 1.0 & - & 1.0 & - \\
\hline 2 & 250 & 136 & 1.3 & 0.26 & 1.0 & 0.94 & 0.7 & 0.75 \\
\hline$\geqslant 3$ & 238 & 119 & 1.9 & 0.01 & 1.7 & 0.30 & 2.4 & 0.21 \\
\hline \multicolumn{9}{|c|}{ New partner at follow upt } \\
\hline Yes & 785 & 439 & 1.8 & 0.003 & 1.2 & 0.42 & 2.2 & 0.26 \\
\hline No & 644 & 408 & 1.0 & - & 1.0 & - & 1.0 & - \\
\hline
\end{tabular}

*People with each STD were compared with the group with no STD.

†Numbers in partners column do not total 2021 because of missing values. 
Table 4 Cohort analysis: associations between sexually transmitted diseases and uncircumcised status $(N=1456)$

\begin{tabular}{llllll}
\hline & \multicolumn{2}{l}{ Crude distribution } & No) & Crude & Adjusted \\
& \cline { 2 - 5 } & Uncircumcised & Circumcised & OR & 95\% CI \\
\hline Without STD & 221 & 634 & 1.0 & 1.0 & \\
Gonorrhea & 36 & 83 & 1.2 & 1.6 & $1.0,2.6$ \\
Chlamydia & 23 & 88 & 0.8 & 0.9 & $0.5,1.5$ \\
Syphilis & 4 & 6 & 1.9 & 1.5 & $0.4,6.1$ \\
\hline
\end{tabular}

^Each model adjusted for age group, race/ethnicity, and site.

†People with each STD were compared with the group with no STD.

After we eliminated variables that were not significantly associated with circumcision such as number of sex partners and sex with a new partner, each multivariate model of disease was adjusted for age group, patient race/ethnicity, and study site (table 4 ). In the adjusted analysis, compared with circumcised men uncircumcised men had a higher risk for gonorrhoea (OR, 1.6; 95\% CI, 1.0 to 2.6), a slightly higher risk of syphilis (OR, 1.5; 95\% CI, 0.4 to 6.1 ), and a similar risk for chlamydia (OR, $0.9 ; 95 \%$ CI, 0.5 to 1.5 ).

\section{Discussion}

The cross sectional and cohort studies found associations between circumcision and gonorrhoea, syphilis, and chlamydia that were similar in magnitude, although most risk estimates were not significant at $p<0.05$. In this analysis, circumcised men had a slightly lower risk than uncircumcised men for gonorrhoea or syphilis, but their risks for acquiring chlamydia were similar. Finding the same results with both study designs increases the likelihood that these findings are valid. The similar results also suggest that there was no strong selection bias operating in our cross sectional study; however, this does not exclude the potential for selection bias in other cross sectional studies of circumcision

GONORRHOEA

We found that lack of circumcision may increase risk for gonorrhoea by $30 \%$ (cross sectional estimate) to $60 \%$ (cohort estimate). Some previous cross sectional studies found no association between circumcision and gonorrhoea, ${ }^{15} 1620$ while other cross sectional studies found similar results with risk estimates ranging from 1.6 to $2.3 . .^{12}{ }^{10}$ The only previous prospective cohort study of gonorrhoea and circumcision $^{13}$ found an increased infection rate for uncircumcised men $(\mathrm{p}<0.1)$. Given the additional strength of cohort studies, the bulk of evidence suggests that circumcision could prevent some gonorrhoea.

SYPHILIS

Both analyses showed a slight increased risk for syphilis among uncircumcised men; however, the small number of syphilis cases in this population limited our statistical power to adequately examine this relation. One previous cross sectional studies mirrored the relation we found ${ }^{20}$ while two others indicated a stronger association. ${ }^{10}$ All of these studies, including ours, lacked an adequate number of cases, and thus precision, to be conclusive. It is difficult to study the risk factors for syphilis in the United States because the incidence is quite low. A future cohort study would need to follow 38415 circumcised men and as many uncircumcised men long enough to see a cumulative incidence of $0.7 \%$ (the annual incidence in our study population) in order to have a power of $80 \%$ to detect a $25 \%$ increase in risk (with $\mathrm{p}=$ $0.05)$.

\section{CHLAMYDIA}

Neither the cross sectional nor the cohort study showed an association between the lack of circumcision and chlamydia infection. Two previous cross sectional studies showed no association ${ }^{110}$ and one showed a slight increase in risk for chlamydia among uncircumcised males. ${ }^{2}$ Considering the majority of the evidence, there does not appear to be a relation between circumcision status and chlamydia. A future cohort study, which could provide additional evidence towards a conclusion, would need to follow 2802 circumcised men and as many uncircumcised men long enough to see a cumulative incidence of $7.6 \%$ (the annual incidence in our study population) in order to have a power of $80 \%$ to detect a $25 \%$ increase in risk (with $\mathrm{p}=0.05)$.

OTHER INFECTIONS

Although we collected data regarding genital warts and genital herpes, we did not report them because the results are difficult to interpret. For genital warts and genital herpes, a new diagnosis does not necessarily represent an incident infection. ${ }^{22-26}$ The true prevalence and incidence of genital warts and genital herpes are very difficult to determine; the tests we used were not sensitive and specific diagnostic tests to determine infection in a symptomatic individual, and most human papillomavirus and herpes infections are asymptomatic. ${ }^{23-26}$

Why might circumcision lower the risk of certain STDs (gonorrhoea, syphilis) but not others? Theories about how circumcision decreases the risk include: (1) trauma of the intact foreskin during sexual intercourse might produce microscopic lesions that increase the susceptibility to sexually transmitted organisms; (2) the environment under the foreskin might enhance the survival of certain infectious agents and thus prolong exposure to them; (3) the epithelium of the glans of uncircumcised men may be thinner and less cornified than in circumcised men, and might provide less of a physical barrier to sexually transmitted microbes; and (4) non-specific balanitis, more common in uncircumcised men, may predispose to certain STDs, possibly because of an inflammatory response. ${ }^{19}$ These theories do not explain why circumcision might influence transmission of gonorrhoea and syphilis, but not chlamydia. However, $T$ pallidum and $N$ gonorrhoeae are known to be highly infectious microbes, ${ }^{27} 28$ and may not require as much inoculum for transmission as chlamydia. Each of these infections affects different populations, so there may be non-biological reasons to explain these different effects. 
The greatest strength of this study was the ability to measure both prevalence and incidence of most STDs of interest. While many studies have been cross sectional or casecontrol in design, only one cohort study has examined the association between circumcision status and the development of any of the STDs that we studied (gonorrhoea). ${ }^{13} \mathrm{~A}$ second strength was that follow up was high for circumcised and uncircumcised men and all were screened for asymptomatic infection, resulting in less bias from treatment seeking behaviour. Lastly, circumcision status was determined by clinicians which is more likely to be valid than asking the participant or his partner. ${ }^{9-12}$

Although our cohort study design reduced the likelihood of selection bias, other potential biases remain. Misclassification bias could have occurred because the original intervention study was not designed specifically to address circumcision status. ${ }^{29}$ Clinicians may not have spent enough time clearly determining or recording circumcision status. This could lead to non-differential measurement error which would bias results toward finding no difference. A more troubling measurement error would be differential misclassification which could occur if clinicians were more likely to classify men with STDs at baseline as uncircumcised. Misclassification of STD at follow up is less likely because our definition of STD was based on laboratory tests which all men had at follow up. Secondly, although this was a large study, the small number of men with disease, especially with syphilis, limited our ability to detect true differences. Finally, we were not able to examine the relation between circumcision and chancroid owing to the lack of cases in our population. Previous studies have shown that circumcision decreases the risk of chancroid by over half. ${ }^{4-8}$ Chancroid is a particularly important infection in some sub-Saharan African areas because it appears to facilitate HIV-1 transmission, ${ }^{4-8}$ and the decreased risk of HIV-1 associated with a decreased risk of chancroid may justify circumcision as an intervention strategy in those areas.

We found suggestive but inconclusive evidence of an association between circumcision and both gonorrhoea and syphilis in our study population. Our findings indicate that circumcision may decrease the risk of incident gonorrhoea by $38 \%$ and incident syphilis by $33 \%$. There have been very few primary studies of circumcision status and STD acquisition. A primary cohort study would be able to address hygiene and other non-biological differences between circumcised and uncircumcised men, reduce study bias, and detect incident infection. Well designed prospective studies are needed if we are to fully understand the relation between circumcision status and STDs and the potential use of circumcision as a prevention intervention.

We thank the Project RESPECT Study Group for collecting the data used in this study. We particularly thank Daniel Newman data used in this study. We particularly
for his assistance with the data analysis.

The members of the Project RESPECT Study Group are as follows: Baltimore: Carolyn Erwin-Johnson, MA; Andrew L
Lentz, MPA; Mary A Staat, MD, MPH; Dawn Sweet, PhD; Jonathan M Zenilman, MD (principal investigator (PI)). Denver: John M Douglas, Jr, MD (PI); Tamara Hoxworth, PhD; Ken Miller, MPH; William McGill, PhD. Long Beach: Ruth Bundy, PhD (co-PI); Laura A Hoyt, MPA; Kevin Malotte, DrPH; Fen Rhodes, PhD (PI). Newark: Michael Iatesta, MA; Eileen Napolitano (co-PI); Judy Rogers, MS; Ken Spitalny, MD (PI). San Francisco: Gail A Bolan, MD (PI); Coleen LeDrew; Kimberly A J Coleman; Luna Hamanel, MSW; Charlotte K Kent, MPH. Nova, Inc, Bethesda, MD: Robert Francis, PhD (PI); Christopher Gordon; Nancy Rosenshine, MA (PI); Carmita Signes. CDC: Sevgi Aral, PhD; Robert H Byers, PhD; Beth Dillon, MSW, MPH; Martin Fishbein, PhD; Sandra Graziano, PhD; Mary L Kamb, MD, MPH; William Killean; James Newhall, PhD; Daniel Newman, MS; Thomas A Peterman, MD, Msc; Karen L Willis, RN. Contributors: RAD, data analyst, manuscript writer, and editor; TAP, principal investigator of primary study, consultant or data analysis, manuscript writer, and editor; MLK, principal nvestigator of primary study, consultant for data analysis, manuscript writer, and editor; CK, principal investigator, San Francisco, CA, study site for data collection, manuscript editor; $\mathrm{JZ}$, principal investigator, Baltimore, $\mathrm{MD}$, study site for data collection, manuscript editor; JD, principal investigator, Denver, $\mathrm{CO}$, study site for data collection, manuscript editor; FR, principal investigator, Long Beach, CA, study site for data
collection, manuscript editor; MI, investigator, Newark, NJ, study site for data collection; manuscript editor.

1 Cook LS, Koutsky LA, Holmes KK. Circumcision and sexually transmitted diseases. Am $\mathcal{f}$ Public Health 1994;84:197-201.

2 Hart G. Factors associated with genital chlamydial and gonococcal infection in males. Genitourin Med 1993;69: gonoco.ca

3 Moses S, Bailey RC, Ronald AR. Male circumcision: assessment of health benefits and risks. Sex Transm Inf $1998 ; 74: 368-73$

4 Nasio JM, Nagelkerke NJD, Mwatha A, et al. Genital ulcer disease among STD clinic attenders in Nairobi: association with HIV-1 and circumcision status. Int $\mathcal{F}$ STD AIDS 1996;7:410-14.

5 Pepin J, Quigley $\mathrm{M}$, Todd J, et al. Association between HIV-2 infection and genital ulcer diseases among male sexually transmitted disease patients in the Gambia. AIDS 1992;6:489-93.

6 Tyndall MW, Ronald AR, Agoki E, et al. Increased risk of infection with human immunodeficiency virus type 1 among uncircumcised men presenting with genital ulcer disease in Kenya. Clin Infect Dis 1996;23:449-53.

7 Telzac EE, Chiasson MA, Bevier PJ, et al. HIV-1 Seroconversion in patients with and without genital ulcer disease: a prospective study. Ann Intern Med 1993;119: $1181-6$

8 Cameron DW, Simonsen JN, D'Costa LJ, et al. Female to male transmission of human immunodeficiency virus type 1: risk factors for seroconversion in men. Lancet 1989;ii: 403-7.

9 Moses S, Plummer F, Bradley JE, et al. The association between lack of male circumcision and risk for HIV infection: a review of the epidemiologic data. Sex Transm Dis 1994;21:201-10.

10 Parker SW, Stewart AJ, Wren MN, et al. Circumcision and sexually transmissible disease. Med F Aust 1983;2:288-90.

11 Seed J, Allen S, Mertens T, et al. Male circumcision, sexually Seed J, Allen S, Mertens T, et al. Male circumcision, sexually
transmitted disease, and risk of HIV. $\mathcal{f}$ Acquir Immune Defic transmitted disease, and risk of HIV.

12 Urassa M, Todd J, Boerma JT, et al. Male circumcision and susceptibility to HIV infection among men in Tanzania. AIDS 1997;11:73-80.

13 Hooper RR, Reynolds GH, Jones OG, et al. Cohort study of venereal disease I. The risk of gonorrhea transmission from infected women to men. Am F Epidemiol 1978;108:136-44.

14 Cook LS, Koutsky LA, Holmes KK. Clinical presentation of genital warts among circumcised and uncircumcised heterosexual men attending an urban STD clinic. Genitourin Med 1993;69:262-4

15 Taylor PK. Rodin P. Herpes genitalis and circumcision. $\mathrm{Br} \mathcal{F}$ Vener Dis 1975;51:274.

16 Smith GL, Greenup R, Takafuji ET. Circumcision as a risk factor for urethritis in racial groups. Am $\mathcal{F}$ Public Health 1987;77:452-4

17 Surick I, McLaughlin M, Chiasson M, et al. HIV infection and circumcision status. New York City Department of Health, New York City, New York. In: Program and Health, New York City, New York. In: Program and abstracts of the International
June 4-9; Abstract TAP 89.

18 Nicoll A. Routine male neonatal circumcision and risk of infection with HIV-1 and other sexually transmitted diseases. Arch Dis Child 1997;77:194-5

19 De Vincenzi I, Mertens T. Male circumcision: a role in HIV prevention? [Editorial review]. AIDS 1994;8:153-60.

20 Donovan B, Bassett I, Bodsworth NJ. Male circumcision and common sexually transmitted diseases in a developed nation setting. Genitourin Med 1994;70:317-20.

$21 \mathrm{Kamb}$ ML, Fishbein M, Douglas JM Jr, et al. Efficacy of risk-reduction counseling to prevent human immunodeficiency virus and sexually transmitted diseases: a randomized controlled trial. $7 A M A$ 1998;280:1161-1167.

22 Parker JDJ, Banatvala JE. Herpes genitalis. Br $\mathcal{F}$ Vener Dis 1967;43:212. 23 Koutsky L. Epidemiology of genital human papillomavirus
infection. Am f Med 1997;102: 3-8. 
24 Koutsky LA, Kiviat NB. Genital human papillomavirus. In: Holmes KK, Sparling PF, Mardh P-A, et al, eds. Sexually
transmitted diseases. 3rd ed. New York: McGraw-Hill, 1999.

25 Fleming DT, McQuillan GM, Johnson RE, et al. Herpes simplex virus type 2 in the United States, 1976-1994. N Engl F Med 1997;337:1105-11

26 Corey L, Wald A. Genital herpes. In: Holmes KK, Sparling PF, Mardh P-A, et al, eds. Sexually transmitted diseases. 3rd ed. New York: McGraw-Hill, 1999.
27 Hook EW, Handsfield HH. Gonococcal infections in the adult. In: Holmes KK, Sparling PF, Mardh P-A, et al, eds. Hill, 1999.

28 Sparling PF. Natural history or syphilis. In: Holmes KK, Sparling PF, Mardh P-A, et al, eds. Sexually transmitted dis-

29 Mertens TE. Estimating the effects of misclassification Lancet 1993;342:418-21. 